Article

\title{
Numerical Study of Alternative Seismic-Resisting Systems for CLT Buildings
}

\author{
Cristiano Loss $\left.{ }^{1,2, *} \mathbb{(}\right)$, Stefano Pacchioli ${ }^{3,4}\left(\mathbb{D}\right.$, Andrea Polastri $^{3}$, Daniele Casagrande ${ }^{3}$, \\ Luca Pozza ${ }^{4}$ and Ian Smith 5 \\ 1 Wood Engineering, University of Northern British Columbia, 499 George St, Prince George, \\ BC V2L1R5, Canada \\ 2 Environmental and Mechanical Engineering, Department of Civil, University of Trento, Via Mesiano 77, \\ 38123 Trento, Italy \\ 3 CNR-IVALSA Trees and Timber Institute, National Research Council of Italy, Via Biasi 75, \\ 38010 San Michele all'Adige, Italy; stefano.pacchioli2@unibo.it (S.P.); polastri@ivalsa.cnr.it (A.P.); \\ casagrande@ivalsa.cnr.it (D.C.) \\ 4 Chemical, Environmental and Materials Engineering, Department of Civil, University of Bologna, \\ Viale Risorgimento 2, 40136 Bologna, Italy; luca.pozza2@unibo.it \\ 5 Faculty of Forestry and Environmental Management, University of New Brunswick, 2 Bailey Dr, Fredericton, \\ NB E3B5A3, Canada; ismith@unb.ca \\ * Correspondence: cristiano.loss@unbc.ca; Tel.: +1-250-960-6715
}

Received: 26 September 2018; Accepted: 14 November 2018; Published: 16 November 2018

\begin{abstract}
Changes to building codes that enable use of materials such as cross-laminated timber (CLT) in mid- and high-rise construction are facilitating sustainable urban development in various parts of the world. Keys to this are the transition to multi-performance-based design approaches along with fewer limitations on heights or the number of storeys in superstructures constructed from combustible materials. Architects and engineers have increased freedom to apply new design and construction concepts and methods, as well as to combine timber with other structural materials. They also have started to develop wall arrangements that optimise interior space layouts and take advantage of the unique characteristics of CLT. This paper discusses the seismic response of multi-story buildings braced with a CLT core and perimeter shear walls anchored to foundations and floor platforms using modern high-capacity angle brackets and hold-downs, or X-Rad connectors. Linear dynamic finite element (FE) models of seismic responses of superstructures of various heights are presented, based on experimentally determined characteristics of wall anchor connections. Particular attention is given to fundamental vibration periods, base shear and uplift forces on walls, as well as inter-story drift. Discussion of FE model results focuses on structural engineering implications and advantages of using CLT to create shear walls, with emphasis on how choice of wall anchoring connections impacts the possible number of storeys and configurations of superstructures. Employing CLT shear walls with X-Rad or other types of high capacity anchoring connections makes possible the creation of building superstructures having eight and potentially more storeys even in high seismicity regions. However, it is important to emphasise that proper selection of suitable arrangements of shear walls for CLT buildings depends on accurate representation of the semi-rigid behaviors of anchoring connections. The linear dynamic analyses presented here demonstrates the need during engineering seismic design practices to avoid use of FE or other design models which do not explicitly incorporate connection flexibilities while estimating parameters like fundamental periods, base shear and uplift forces, as well as inter-story drift.
\end{abstract}

Keywords: buildings; connections; cross-laminated timber (CLT); design; seismic performance; superstructures; sustainable development; timber; walls 


\section{Introduction}

\subsection{Background}

In response to a growing population worldwide, communities are imposing strict guidelines regarding energy usage, environmental sustainability, and land-use, especially in urban areas [1]. In particular, land-use consideration forces trends toward increased urban population densification and increased building heights. Industries are responding to the challenges and opportunities by developing suitable technologies for the renovation and construction of buildings, based on minimisation of lifecycle energy consumption and atmospheric carbon dioxide emissions [2].

Using traditional and modern engineered wood products as structural materials offers advantages for renovation or construction of mid- and high-rise buildings. Physical and mechanical characteristics of wood-based and related assembly techniques permit high levels of prefabrication and minimise construction time and costs. In addition, wood-based products are widely regarded as carbon-neutral material choices, and their low density to mechanical property ratios make them highly suited for lightweight building superstructures [3]. Employing lightweight superstructures can minimise construction costs for superstructures themselves and the foundations on which they rest. They also can increase architectural and structural engineering options in, for example, the design of relatively tall buildings in earthquake-prone regions.

Building codes in various countries have been transitioning, over the last two decades or so, from documents which prescriptively state how buildings should be designed and constructed, to documents which encourage design and construction of buildings which meet multi-performance-based objectives [4]. Initially, this was driven by a wish to liberate architectural and engineering capabilities from the straitjacket of prescriptive fire performance-related limits on maximum building heights and number of storeys. Now, however, consideration also extends to building performance under a broad spectrum of safety and operational performance-related scenarios. Transition away from sometimes hugely restrictive prescriptive limits on heights of building superstructures constructed from wood-products and other so-called combustible materials is arguably the greatest liberation of urban architecture since structural-steel framing products permitted construction of first-generation skyscrapers.

Modern mid-rise wood/timber construction typologies developed so far are strongly oriented towards use of the class of products known collectively as cross-laminated timber (CLT) as the sole primary superstructure material [5]. Choice of CLT has typically reflected that it is now a widely available relatively lightweight material having comparable strength and stiffness characteristics to similar dimension reinforced concrete beams and slab elements. The trend in high-rise building typologies is to use CLT and other high-performance wood products in combining with reinforced concrete [6] or structural steel [7] to create superstructures. In either case, engineers seek to optimise superstructure designs in ways that meet relevant performance objectives for fire, earthquakes, wind, vibration and acoustical serviceability, etc., in line with relevant code requirements [8]. Looking to the future, the likely trend is toward the creation of a broad range of 'hybrid' solutions distinctly different from 'conventional' (traditional) wood/timber construction methods. For instance, the potential of hybrid systems employing wood products as a primary superstructure material has been demonstrated by construction of the Brock Commons Tall Wood Building in Canada. That building is a student residence on the Vancouver campus of the University of British Columbia, with 18 storeys and a superstructure height of $53 \mathrm{~m}$. It combines massive timber-frame systems with two reinforced concrete cores to satisfy seismic force resisting systems (SFRS) and other structural performance design objectives [9].

\subsection{CLT Buildings}

Developed in Europe, CLT was initially used in plate form to create both perimeter and internal walls and roofs, and elevated floors of low-rise residential and mercantile buildings, with element 
thicknesses selected to resist effects of vertical and horizontal design forces. Preferred design solutions mostly resulted in box-like arrangements with individual CLT elements tied together at junctions and walls anchored to foundations or other supporting platforms. Supporting research focused on characterisation of material [10] and connections [11] properties, as well as studying constructed systems. The Italian SOFIE-Construction System Fiemme-Project carried out by the Trees and Timber Institute of the National Research Council of Italy [12] was a landmark undertaking in the sense that it extended consideration of what could be constructed using CLT, including study of mid-rise residential buildings from structural and non-structural multi-performance-objective perspectives. Complementary studies were conducted at the University of Trento in Italy and the University of Ljubljana in Slovenia. Tests at the University of Trento [13] related to the seismic performance of individual CLT shear walls, whereas those at the University of Ljubljana [14] assessed behaviour of two-dimensional shear-wall systems subjected to different types of forces and having various boundary conditions. Since those pioneering efforts, researchers in other countries have helped expand the scope of investigations. Illustrative of this is work at the Canadian industry-led R\&D institute FPInnovations where seismic performance of three-dimensional CLT structures was studied [15]. In aggregate, the confidence reached around one decade ago drove architects and engineers to design and construct various low- to mid-rise buildings in diverse locations, mostly, but not only, within Europe. During the last decade, use of CLT has evolved considerably, expanding into the mid- to high-rise building sectors [16]. For mid-rise buildings, interest has been devoted mostly to developing high structural systems allowing the creation of large open interior-spaces and giving flexibility in interior layouts.

Effects of seismic actions on superstructures constructed fully or partially from CLT have been central to structural R\&D efforts because of the special performance demands on lateral force resisting systems (LFRS) that can be involved [17]. Crucial to performances of LFRS, whether they are intended to resist effects of wind, seismic or other design forces, are the connections which link CLT elements to one another or to other elements involved in the pathways by which effects of forces flow into building foundations. Because increased building heights tend to magnify the flows of forces which connections must handle, part of necessary studies has been creation of new types of high capacity connections and connectors. Especially for LFRS, which must act as SFRS, avoiding localised brittle failures in connections is important because such failure can cascade into system-level damage. Scotta et al. [18], for example, studied ways of avoiding brittle failure mechanisms in large shear wall systems involving balloon-type construction methods [19]. Recent experimental and numerical investigations have put heavy focus on ways of reliably handling force flows in SFRS of quite tall hybrid buildings in high seismicity regions [20].

\subsection{Scope of the Paper}

The focus of this paper is the seismic response of multi-story buildings braced with CLT core and perimeter shear walls assembled using high-capacity angle brackets and hold-downs, or X-Rad connectors. Particular consideration is given to the influences that choices of connection types have on the fundamental periods, base shear and uplift forces on CLT shear walls, and inter-storey drift. This focus is because these primary engineering parameters determine the practicality of multi-story buildings with CLT shear walls. The adopted method is linear dynamic analyses performed using finite element $(\mathrm{FE})$ models which incorporate elements calibrated to match experimentally-determined behaviours of various types of connections. Results of FE analyses show the effects the number of storeys, and therefore superstructure height, have on the SFRS response as a function of shear-wall configurations and the type of connections a design engineer might select. 


\section{Connection Technologies for CLT Buildings}

\subsection{Multi-Storey Platform Construction}

Traditionally, low-rise, and occasionally mid-rise, multi-storey wood superstructures are commonly constructed using the so-called light-timber frame system (LTFS) according to the platform method of construction [21]. Under that approach, buildings are erected in a sequence where each added floor platform becomes the working surface for construction of the next storey, greatly facilitating assembly of the entire system. LTFS shear walls are anchored to the foundation and elevated floor platforms by anchoring connections of types suited to demands of particular projects. Anchoring connections fulfil hold-down and shear resistance functions associated with resisting potentially damaging effects of force flows in LFRS resulting from wind, seismic or other forces. Owing to the proven reliability and practicality of LTFS superstructures, it is a natural extension of traditional wood construction methods to construct superstructures containing CLT shear walls according to the platform method. This said, it is important to acknowledge differences in physical and mechanical characteristics of light-timber frame and CLT wall elements, and differences in characteristics of floor platforms to which they are anchored. Relatively high in-plane rigidity of CLT means that wall elements tend to rock and slide relative to their foundations or supporting elevated platforms, rather than tending to flex and slide as parts of LFRS. Choice of connection methods for CLT platform systems need to accommodate rocking of wall elements and limit sliding. The most common types of CLT shear wall anchoring connections to date have been hold-down ties and angle brackets capable of resisting uplift and sliding forces, respectively [22]. Initially, when heights and number of storeys of superstructures were limited (circa four or fewer storeys), using anchoring as per LTFS often sufficed. However, as demand to create taller buildings increases, the ability to satisfactorily anchor walls using common connections diminishes. Attention therefore became more directed toward development of new anchoring connection methods and solutions suited explicitly to creation of safe and serviceable tall LFRS containing CLT shear walls, with emphasis on the technical demands for buildings located in high seismicity regions [23-25].

CLT anchoring connections are the primary elements within SFRS designed to dissipate energy during seismic events and therefore play a crucial role in limiting superstructure motions and preventing any localised damage propagating into system-level damage. Initial research on performance of relatively simple anchoring connections was for evaluating their strength, stiffness and ductility characteristics, as well as creating a basis or simple equivalent static force engineering design practices suited to design of low-rise superstructures [26,27]. More recent attention has switched to the attainment of an in-depth understanding of mechanical behaviours of connections and creation of design methods explicitly addressing avoidance of brittle failures, consistent with the implementation of capacity-based design procedures [28,29]. Studies are currently underway with the objective of fully reconciling questions related to the necessary consistency between how CLT anchoring connections behave, how engineers should predict behaviours of SFRS, and what guidance codes should give to engineers designing superstructures containing CLT shear walls [30]. The results and discussion below are part of this refined focus.

\subsection{X-Rad System: Concept and Construction}

CLT buildings equipped with X-Rad connectors have one connector installed at each corner of each CLT element as illustrated in Figures 1 and 2. This enables creation of SFRS that are highly prefabricated, and which, from a structural performance perspective, create unambiguous pathways by which forces flow through the entire system and into building foundations. This contrasts markedly with monolithic SFRS constructed from wood (e.g., LTFS) and various non-wood materials (e.g., reinforced concrete, masonry) which are typified by uncertainties in exactly how forces generated by various design-loading scenarios will flow and where potential vulnerabilities exist in SFRS. At construction sites, CLT fitted with X-Rad connectors are attached to special steel plates anchored to foundations or other supports, 
Figure 2a. Standard steel bolts are used to connect X-Rad connectors to the steel plates making pin connections between CLT elements. X-Rad connectors themselves consist of an outer metallic box, an inner hardwood core and six VGS $11 \times 350$ full-threaded self-tapping screws (STS) [31], Figure 1c. The six STS are installed at two angles of inclination to ensure forces flow reliably into CLT elements in a manner which will not cause brittle failure, irrespective of the instantaneous direction in which the resultant force flows through a bolt at any particular pin connection. The intent is that gaps between CLT elements be filled by insulation or other materials to ensure proper functioning of buildings in terms of their ability to meet other multi-performance design objectives (e.g., fire, acoustical, or thermal performance). However, those materials and others elements/materials attached to CLT elements for architectural or engineering performance reasons must be of types that do not negate the intent of how forces will flow through SFRS if a design level event occurs. A further intent is that any damage to buildings caused by earthquakes or other extreme events would be superficial and the response of the SFRS will have been, in essence, elastic.

$R \& D$ leading to the creation of the X-Rad systems and connectors was carried out in Italy by the University of Trento and CNR-IVALSA, and in Austria by the Technical University of Graz [32-34].

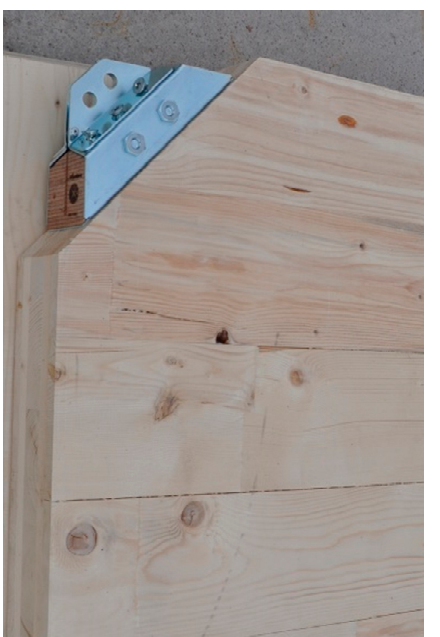

(a)

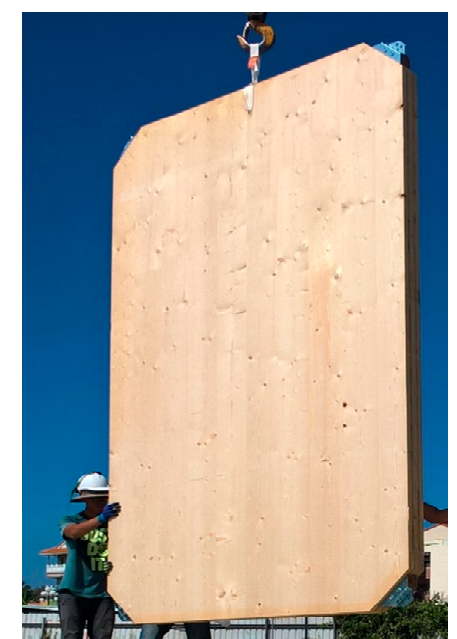

(b)

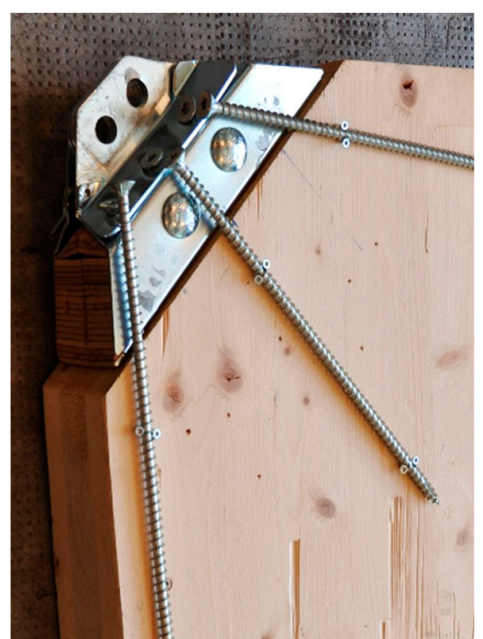

(c)

Figure 1. (a) X-Rad connector installed at one corner of a cross-laminated timber (CLT) panel; (b) CLT wall with connectors ready to be installed; (c) mock-up of X-Rad connector with in-view of its different parts (photos courtesy of Rothoblaas).

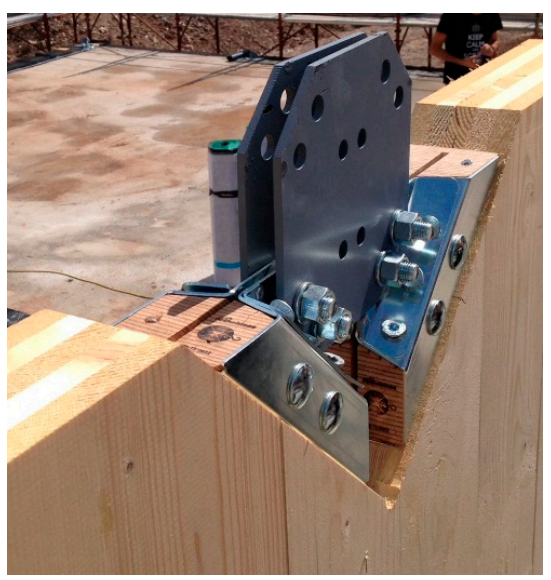

(a)

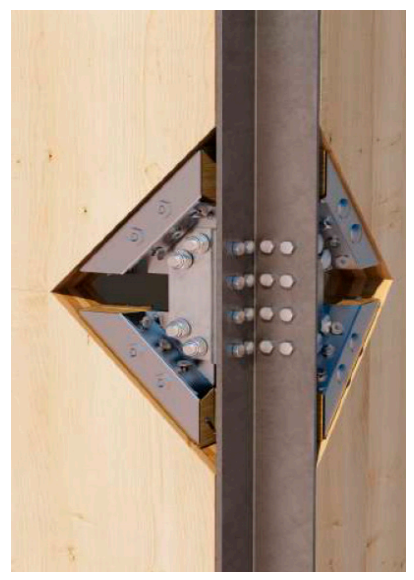

(b)

Figure 2. (a) Steel plate used to join two adjacent CLT panels equipped with X-Rad connectors (photo courtesy of Rothoblaas); (b) prototype of steel profiles used at the corners of a building. 


\section{Numerical Studies of SFRS}

\subsection{Cases Study}

The case study presented here demonstrates the influence of anchoring systems on dynamic responses and earthquake-induced force flows within buildings having CLT core and perimeter CLT shear walls. Wall arrangement of the three-storey building superstructure illustrated in Figure 3 is used as the reference point for assessing effects of variations in SFRS characteristics, such as the number of storeys and shear wall anchoring connection methods. The reference building and its SFRS were chosen as realistic representations of low-rise buildings currently designed and constructed in Europe and Canada according to normal levels of structural engineering design and employing standard types of CLT and connection products. In total, the case study addresses three superstructure/SFRS heights: three, five and eight storeys of $3 \mathrm{~m}$ each. Five storey systems represent cases toward the top range of buildings considered low-rise, and eight storey systems are contemporarily representative of buildings considered medium-rise. Studied buildings would, in practice, be erected according to standard platform construction methods.

In all considered cases, shear walls are placed symmetrically at the corners of buildings because it is the most structurally efficient way of controlling torsional motions of superstructures and SFRS about their vertical axes during seismic, or other, design events. Incorporation of a CLT core at the centre of buildings meets fire and other design objectives, as well as being efficient in terms of generalised structural (not just seismic or wind performance), constructability and material use considerations. Formal SFRS design practices followed during the design of the case study systems were those of Eurocode 8 [35]. However, this does not limit generality of findings reported below because other international design codes contain technically similar provisions.

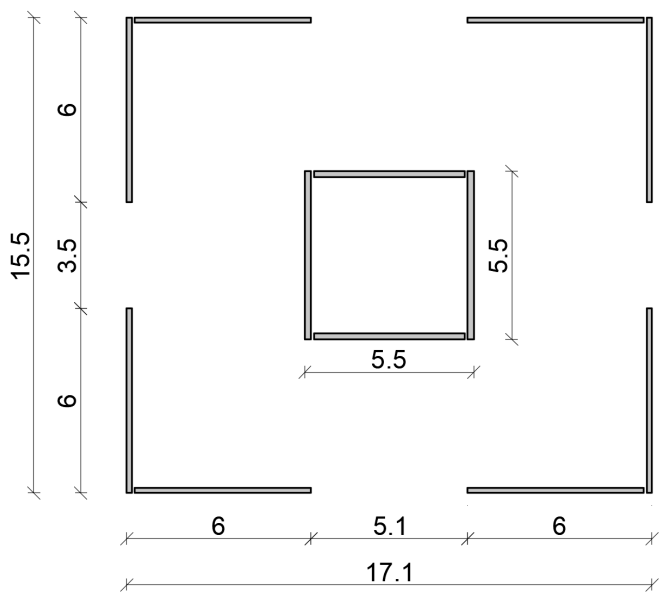

(a)

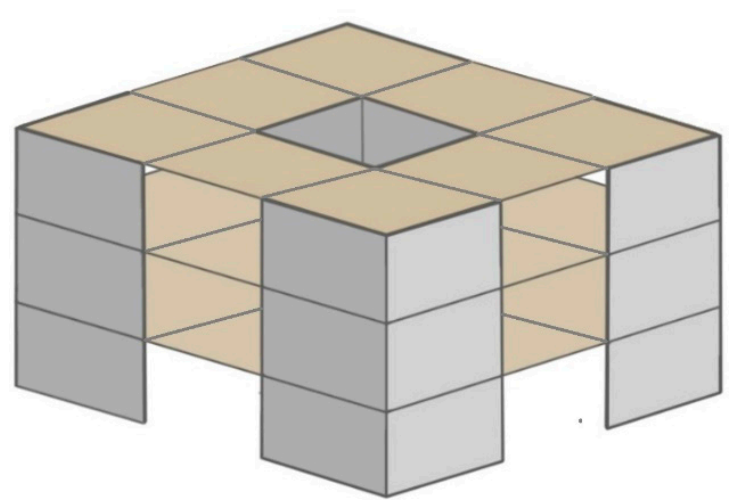

(b)

Figure 3. Reference building: (a) building footprint and shear-wall arrangement; (b) axonometric view (dimensions in $\mathrm{m}$ ).

The reference and other systems employ glulam beam-and-column frameworks to resist effects of vertical design loads, as good practice for ensuring existence of well-defined load-paths and avoiding potential for disproportionate damage if substructures are overloaded [8,36]. Within case studies, systems having standard CLT anchoring connections consisting of hold-down ties and angle brackets capable of resisting sliding forces are referred to as type A systems, whereas systems having X-Rad connections are referred to as type B systems. A homogeneous distribution of connections was considered to make SFRS A and B consistent in terms of installed anchoring devices along the height of buildings. Figure 4 shows the connection arrangements for type A and B systems. The logic of type A systems is that, consistent with already-mentioned principles of avoiding ambiguity in how forces 
flow through SFRS, there is functional separation between flow pathways for vertical and horizontal forces at every junction between parts of SFRS.

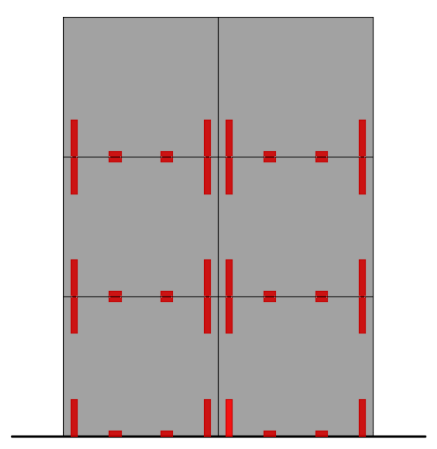

(a)

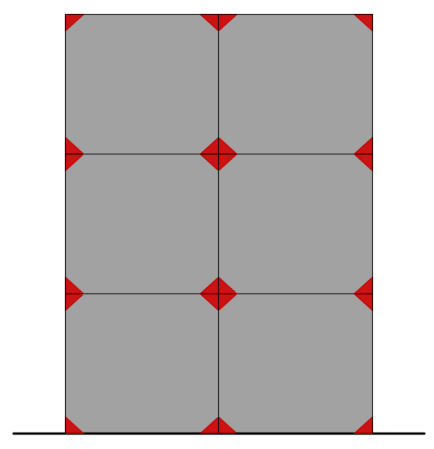

(b)

Figure 4. Connection arrangements for shear walls; (a) A-3 system; (b) B-3 system.

\subsection{Design of SFRS}

Thicknesses of CLT elements were established initially for three, five and eight storey buildings based on dead and live gravity loads on elevated floors of $4.5 \mathrm{kPa}$ and $3.0 \mathrm{kPa}$, respectively. Such loads correspond to residential buildings. Seismic actions were calculated according to the Eurocode 8 [35] simplified procedure assuming buildings are located in a high seismicity zone (Perugia, Italy) on soil type C (deep deposits of sand, gravel or clay), with an expected reference peak ground acceleration of $0.35 \times g$ [37]. In determining masses associated with gravity loads, the combination factor $\Psi_{E i}$ was taken as 0.6 , and the reference behaviour factor accounting for the system ductility $q_{0}$ as 2.0. As shear wall anchoring connections were not proportional to the storey seismic horizontal demand, the reduction factor $k_{\mathrm{r}}$, was assumed equal to 0.8 , in accordance with code provisions [35] and prior studies [38]. As a result, the behaviour factor $q$, obtained by multiplying $q_{0}$ by $k_{\mathrm{r}}$, was assumed equal to 1.6. Therefore, the $q$-value assumed in the design of SFRS was close to that used when elastically designing low energy dissipation capacity systems. Table 1 summarises initial design characteristics of each case study system, with $n$ being the number of storeys, $H$ the superstructure/SFRS height, $T_{1}$ * the fundamental period calculated according to the simplified expression $T_{1}^{*}=0.05 H^{0.75}$ [35], $W$ the total building gravity force, and $S_{\mathrm{d}_{-} e l}\left(T_{1}^{*}\right)$ and $S_{\mathrm{d}}\left(T_{1}^{*}\right)$ the elastic and the design response spectrum accelerations, respectively, calculated at the ultimate limiting state (ULS).

Table 1. Initial design characteristics of case study seismic force resisting systems (SFRS).

\begin{tabular}{lccc}
\hline $\boldsymbol{N}$ & $\mathbf{3}$ & $\mathbf{5}$ & $\mathbf{8}$ \\
\hline $\boldsymbol{H}$ & $9.0 \mathrm{~m}$ & Type A systems & $24.0 \mathrm{~m}$ \\
$\boldsymbol{T}_{\mathbf{1}}{ }^{*}$ & $0.26 \mathrm{~s}$ & $0.38 \mathrm{~s}$ & $0.54 \mathrm{~s}$ \\
$\boldsymbol{W}$ & $2759 \mathrm{kN}$ & $4767 \mathrm{kN}$ & $7778 \mathrm{kN}$ \\
$\boldsymbol{S}_{\mathbf{d} \_ \text {el }}\left(\boldsymbol{T}_{\mathbf{1}}{ }^{*}\right)$ & $0.82 \times g$ & $0.82 \times g$ & $0.78 \times g$ \\
$\boldsymbol{S}_{\mathbf{d}}\left(\boldsymbol{T}_{\mathbf{1}}{ }^{*}\right)$ & $0.51 \times g$ & $0.51 \times g$ & $0.49 \times g$ \\
\hline
\end{tabular}

The number and dimensions of shear wall anchoring connections were chosen to satisfy strength requirements according to the iterative procedure developed by Polastri and Pozza [39], accounting for the estimated $T_{1}{ }^{*}$ period (Table 1 ). This procedure accounts for experimentally determined stiffness and capacity of individual types of connectors. It requires iterative determination of forces in each CLT shear-wall element based on equivalent static force linear analysis until estimated force flows in anchoring connections match assigned stiffness and strengths of connectors. 


\subsection{Mechanical Properties of Materials and Connections}

Design calculations were based on use of European-type CLT manufactured from class C24 wood boards [40], assuming mechanical properties given in commercial product assessment documentation [41].

For the design of type A systems, WHT 620 anchors [42] were used as hold-downs and TITAN TTF200 [42] as angle brackets attached to CLT by thirty-two $4 \times 60 \mathrm{~mm}$ and thirty $4 \times 60 \mathrm{~mm}$ Anker nails, respectively. The number of anchoring systems and related nails were derived based on the procedure previously explained in order to withstand seismic design actions at every storey. Table 2 reposts the typical storey connection pattern adopted for the building in system configuration $\mathrm{A}$ at varying heights. Adopted stiffness values, $k$, were experimentally determined by CNR-IVALSA and the University of Trento [43] following the increasing displacement amplitude test protocol (method b) of EN 12,512 [44], with resulting $k$ values of $13.2 \mathrm{kN} / \mathrm{mm}$ for WHT 620 anchors, and $8.2 \mathrm{kN} / \mathrm{mm}$ for TITAN TTF200 brackets, respectively. Conversely, capacities, $F_{c}$, of connection devices were determined according to pertinent European Technical Documents (ETA) [45,46], with resulting $F_{\mathrm{c}}$ values of $93.7 \mathrm{kN}$ for WHT 620 and $39.1 \mathrm{kN}$ for TITAN TTF200 brackets. For the design of type B systems, in addition to X-Rad connections placed at every CLT panel corner, tie-downs were used when resulting tensile seismic actions were higher than their uplift capacity. Specifically, for the five and eight storey buildings, additional tie-downs were designed. The shear capacity of X-Rad connections were always adequate to satisfy seismic shear force demand in every building. For type B systems with $X$-Rad connections, the experimental approach was used to assess both $k$ and $F_{\mathrm{c}}$ values, using test data from [34,47]. Adopted $k$ and $F_{\mathrm{c}}$ were $13.4 \mathrm{kN} / \mathrm{mm}$ and $129 \mathrm{kN}$ when loaded in pure tension or shear.

In recognising that the uniform distribution in the height of the hold-downs and angle brackets does not allow for maximising dissipation of connections, it should be noted that experimental-based stiffness values of connections are available only for some type of devices, like those used in this study.

Table 2. Design pattern of connections for single shear wall adopted in type A and type B building systems.

\begin{tabular}{ccccccc}
\hline & \multicolumn{2}{c}{ 3-Storey } & \multicolumn{2}{c}{ 5-Storey } & \multicolumn{2}{c}{ 8-Storey } \\
\hline System & A-3 & B-3 & A-5 & B-5 & A-8 & B-8 \\
\hline $\begin{array}{c}\text { Shear } \\
\text { reconnection }\end{array}$ & 6 TTF200 & 4 X-Rad & 8 TTF200 & 4 X-Rad & 9 TTF200 & 4 X-Rad \\
\hline $\begin{array}{c}\text { Uplift resistant } \\
\text { connection }\end{array}$ & 2 WHT 620 & 1 X-Rad & 2 WHT 620 & 1 X-Rad & 3 WHT 620 & 1 X-Rad \\
\hline Tie-down & $/$ & $/$ & $\begin{array}{c}100 \times 25 \\
\mathrm{~mm}^{2} \text { S355 } \\
\text { steel plate }\end{array}$ & $/$ & $\begin{array}{c}150 \times 25 \\
\text { mm }^{2} \text { S355 } \\
\text { steel plate }\end{array}$ \\
\hline
\end{tabular}

\subsection{Finite Element (FE) Models}

Finite element models were built in SAP $2000^{\circledR}$ using mechanical properties reported in Section 3.3 adjusted in the case of CLT according to recommendations of Dujic et al. [48]. Linear-elastic discretization was adopted based on shell-element and equivalent-spring representations of CLT and connections respectively, Figures 5 and 6. For type A systems (Figure 5a) springs representing hold-downs and angle brackets were positioned vertically and horizontally, respectively, to ensure uncoupled behaviour, consistent with the intent for force flows through them to be uncoupled [49]. For type B systems, X-Rad connections (Figure $5 b$ ) were modeled by two orthogonal uniaxial springs calibrated to represent elastic stiffness in vertical and horizontal directions, consistent with creation of point pinned connections. In the cases of type B systems having five or eight storeys, models contained supplementary tie elements (shown as bold vertical lines in Figure 5b) at edges of shear 
walls. Supplementary ties were added only when force flows would otherwise exceed capacities of X-Rad connectors. Figure 6 shows three-dimensional FE representations of complete SFRS systems.

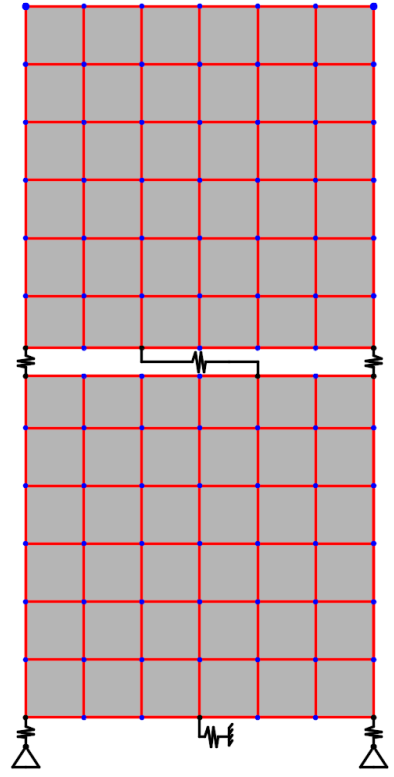

(a)

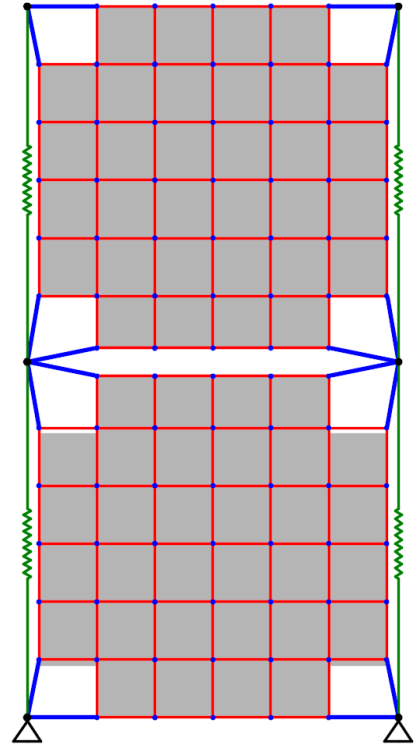

(b)

Figure 5. Finite element (FE) representation of shear wall: (a) type A systems; (b) type B systems.

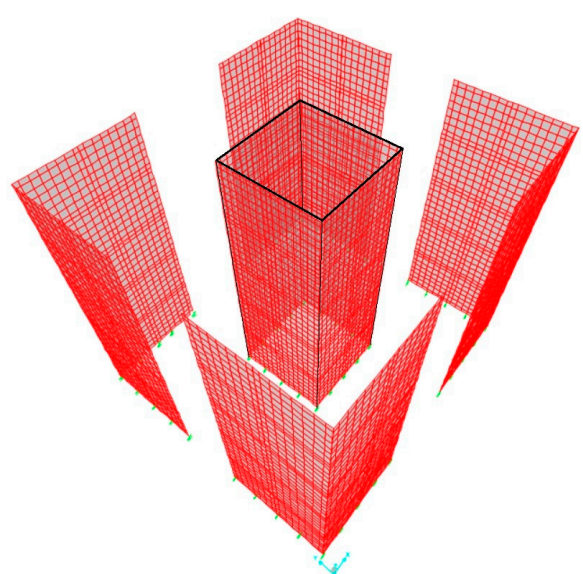

(a)

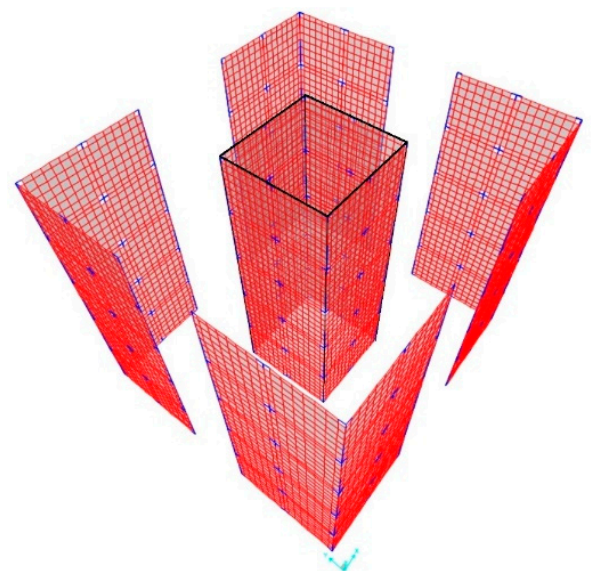

(b)

Figure 6. FE models of complete SFRS: (a) type A system; (b) type B system.

\subsection{Analyses}

Numerical modal analyses (MA) were performed for each SFRS to determine free-vibration mode shapes and frequencies, and the fundamental period $T_{1, \mathrm{FEM}}$. Modal response spectrum analyses (MRSA) were then carried out for the ultimate and damage limiting states, to determine maximum force demands on the CLT anchoring connections and lateral displacements at each storey, respectively.

For MA, the mass of each structure was assigned considering gravity loads as recommended by Eurocode 8 [35]. In the case of MRSA, the response was obtained using the complete quadratic combination (CQC) modal technique [35]. Vertical loads of the MA and the effective masses of MRSA were concentrated at each floor level and uniformly distributed across floor areas. 


\section{Results}

Tables 3-7 summarise MA and MRSA results as functions of the number of storeys and system type. Values of fundamental period, $T_{1}{ }^{*}\left(=0.05 H^{0.75}\right.$ [35]), in Table 3 were calculated according to the simplified expression of Eurocode 8 , as comparisons to $T_{1, \mathrm{FEM}}$ determined from MA. Table 3 also includes estimated periods divided by the number of storeys $\left(T_{1, \mathrm{E}}, T_{1, \mathrm{FEM}, n}\right)$, as an indication of the empirical expectation that periods are directly proportional to heights of building superstructures. The building's base shear at the ULS, $V_{\text {tot }}$ and its dimensionless value, $V_{\text {tot, } \mathrm{W}},\left(=V_{\text {tot }} / W\right)$ are reported in Table 4 , together with average base shear per unit length of shear wall, $v_{\mathrm{sw}}$. Table 5 lists the maximum uplift $N_{H D}$ and tie-down forces $T_{H D}$ at ULS for perimeter and core shear walls, as well as normalised dimensionless values $N_{H D, W}\left(=N_{H D} / W\right)$ and $T_{H D, W}\left(=T_{H D} / W\right)$. In this context, hold-down forces apply to anchoring connectors, and tie-down forces to supplementary ties added to taller type B systems. Table 6 gives maximum lateral displacements, $\Delta$, at each storey for the displacement limiting state (DLS). Table 7 shows maximum inter-storey drifts, $\theta_{\max }$, and components of those inter-storey drifts attributable to deformation of hold-downs, $\theta_{\max }{ }^{\text {rok }}$, angle brackets, $\theta_{\max }$ she and CTL elements, $\theta_{\max }{ }^{\mathrm{CLT}}$.

Table 3. Fundamental periods.

\begin{tabular}{|c|c|c|c|c|c|c|}
\hline \multirow{2}{*}{$\begin{array}{c}\text { Fundamental Period } \\
\text { System }\end{array}$} & \multicolumn{2}{|c|}{ 3-Storey } & \multicolumn{2}{|c|}{ 5-Storey } & \multicolumn{2}{|c|}{ 8-Storey } \\
\hline & A-3 & B-3 & A-5 & B-5 & A-8 & B-8 \\
\hline$T_{1}^{*}(\mathrm{~s})$ & \multicolumn{2}{|c|}{0.26} & \multicolumn{2}{|c|}{0.38} & \multicolumn{2}{|c|}{0.54} \\
\hline$T_{1, \text { FEM }}(\mathrm{s})$ & 0.38 & 0.64 & 0.59 & 0.69 & 1.14 & 0.97 \\
\hline$T_{1, \mathrm{FEM}, n}(\mathrm{~s})$ & 0.13 & 0.21 & 0.12 & 0.14 & 0.14 & 0.12 \\
\hline$T_{1, \mathrm{E}}(\mathrm{s})$ & \multicolumn{2}{|c|}{0.30} & \multicolumn{2}{|c|}{0.50} & \multicolumn{2}{|c|}{0.80} \\
\hline
\end{tabular}

Table 4. Base shear forces at ultimate limiting state (ULS).

\begin{tabular}{cccccccc}
\hline Base Shear and Forces on Walls & \multicolumn{2}{c}{ 3-Storey } & \multicolumn{2}{c}{ 5-Storey } & \multicolumn{2}{c}{ 8-Storey } \\
\hline System & A-3 & B-3 & A-5 & B-5 & A-8 & B-8 \\
\hline$V_{\text {tot }}(\mathbf{k N})$ & 1368 & 1103 & 1853 & 1840 & 2004 & 2265 \\
$V_{\text {tot }, W}(-)$ & 0.50 & 0.40 & 0.39 & 0.38 & 0.26 & 0.29 \\
$\boldsymbol{v}_{\text {sw }}(\mathbf{k N} / \mathbf{m})$ & 39 & 30 & 53 & 51 & 55 & 65 \\
\hline
\end{tabular}

Table 5. Uplift forces at ULS.

\begin{tabular}{ccccccc}
\hline Uplift Force & \multicolumn{2}{c}{ 3-Storey } & \multicolumn{2}{c}{ 5-Storey } & \multicolumn{2}{c}{ 8-Storey } \\
\hline System & A-3 & B-3 & A-5 & B-5 & A-8 & B-8 \\
\hline \multicolumn{7}{c}{ Perimeter walls } \\
$N_{H D}(\mathbf{k N )}$ & 228 & 167 & 260 & 102 & 340 & 104 \\
$\boldsymbol{N}_{H D, W}(-)$ & 0.08 & 0.06 & 0.06 & 0.02 & 0.04 & 0.01 \\
$\boldsymbol{T}_{H D}(\mathbf{k N})$ & - & - & - & 234 & - & 378 \\
$\boldsymbol{T}_{H D, W}(-)$ & - & - & - & 0.05 & - & 0.04 \\
\hline & \multicolumn{7}{c}{ Core walls } \\
$N_{H D}(\mathbf{k N})$ & 258 & 150 & 283 & 123 & 403 & 139 \\
$\boldsymbol{N}_{H D, W}(-)$ & 0.09 & 0.05 & 0.06 & 0.03 & 0.05 & 0.02 \\
$\boldsymbol{T}_{H D}(\mathbf{k N})$ & - & - & - & 351 & - & 522 \\
$\boldsymbol{T}_{H D, W} \mathbf{( - )}$ & - & - & - & 0.05 & - & 0.07 \\
\hline
\end{tabular}


Table 6. Lateral displacements at displacement limiting state (DLS).

\begin{tabular}{cccccccc}
\hline Displacement & Level & \multicolumn{2}{c}{ 3-Storey } & \multicolumn{2}{c}{ 5-Storey } & \multicolumn{2}{c}{ 8-Storey } \\
\hline System & $\boldsymbol{i}$ & A-3 & B-3 & A-5 & B-5 & A-8 & B-8 \\
\hline $\boldsymbol{\Delta}_{\mathbf{1}}(\mathbf{m m})$ & 1 & 12 & 14 & 16 & 15 & 20 & 20 \\
$\boldsymbol{\Delta}_{\mathbf{2}}(\mathbf{m m})$ & 2 & 27 & 34 & 31 & 29 & 41 & 42 \\
$\boldsymbol{\Delta}_{\mathbf{3}}(\mathbf{m m})$ & 3 & 42 & 53 & 47 & 48 & 61 & 62 \\
$\boldsymbol{\Delta}_{\mathbf{4}}(\mathbf{m m})$ & 4 & - & - & 61 & 57 & 81 & 61 \\
$\boldsymbol{\Delta}_{\mathbf{5}}(\mathbf{m m})$ & 5 & - & - & 75 & 76 & 99 & 62 \\
$\boldsymbol{\Delta}_{\mathbf{6}}(\mathbf{m m})$ & 6 & - & - & - & - & 118 & 76 \\
$\boldsymbol{\Delta}_{\mathbf{7}}(\mathbf{m m})$ & 7 & - & - & - & - & 135 & 92 \\
$\boldsymbol{\Delta}_{\mathbf{8}}(\mathbf{m m})$ & 8 & - & - & - & - & 152 & 103 \\
\hline
\end{tabular}

Table 7. Inter-storey drifts at DLS and their components.

\begin{tabular}{ccccccc}
\hline Drift & \multicolumn{2}{c}{ 3-Storey } & \multicolumn{2}{c}{ 5-Storey } & \multicolumn{2}{c}{ 8-Storey } \\
\hline & A-3 & B-3 & A-5 & B-5 & A-8 & B-8 \\
\hline $\boldsymbol{\theta}_{\max } \mathbf{( \% )}$ & 0.41 & 0.47 & 0.52 & 0.48 & 0.65 & 0.60 \\
$\boldsymbol{\theta}_{\max }$ rok (\%) & 0.17 & 0.12 & 0.30 & 0.08 & 0.40 & 0.10 \\
$\boldsymbol{\theta}_{\max }$ she (\%) & 0.11 & 0.20 & 0.13 & 0.24 & 0.17 & 0.32 \\
$\boldsymbol{\theta}_{\max }{ }^{\text {CLT }} \mathbf{( \% )}$ & 0.13 & 0.15 & 0.09 & 0.16 & 0.08 & 0.18 \\
\hline
\end{tabular}

\section{Discussion}

\subsection{Fundamental Elastic Period}

Table 3 indicates that, except for three storey system (i.e., B-3 has no supplementary tie-downs), type A and type B building superstructures have roughly similar fundamental periods for the same building height, with fundamental periods based on. However, this should not be taken as a finding to extrapolate to other systems, because in other cases (e.g., more slender or sculpted superstructures) different mode shapes may determine fundamental periods for superstructures of different heights. Agreement between $T_{1}{ }^{*}$ values calculated according to the simplified expression of Eurocode 8 and

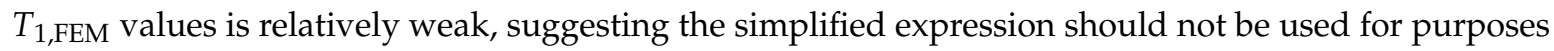
other than seeding iterative design solution methods (as in Section 3.5) based on FE or other detailed MA and MRSA methods.

The fundamental period of system B-8 with X-Rad connectors and supplementary tie-downs is reduced by $17.5 \%$ compared to system A- 8 with high-capacity conventional connections. This means system B-8 has a lower fundamental modal stiffness than system A-8. Conversely, for five- and three-storey building superstructures with conventional anchoring connections (hold-downs and angle brackets) the fundamental modal stiffness is higher than for the corresponding system with X-Rad connectors. The importance of this is that it is a strong indication that whatever type of seismic design practices engineers employ, estimation of the fundamental period should be carried out by a method (or methods) which explicitly accounts for how the presence of semi-rigid connections influences $T_{1}$. The finding is also an indication that empirical formulas, calibrated, for example, based on experimental field MA observations, will have variable and possibly limited accuracy except if matched to data they were calibrated against. By extension, seismic design practices based on equivalent static force analysis methods will only yield suboptimal solutions even when rules on regularity and heights of designed superstructures obey stipulations of Eurocode 8 [35] or other applicable design codes. For this reason, the authors strongly recommend the use of modal response spectrum analysis methods, such as the procedure proposed by Polastri and Pozza [39], be adopted as the basis of building designs having CLT shear walls. Experimental information, or guidance in Eurocode 5 [50], can provide necessary connection stiffness information [17]. 


\subsection{Base Shear Forces}

As should be expected, results in Table 4 show an increase in the total base shear at the ULS, $V_{\text {tot }}$, as heights of buildings increase, with magnitudes being similar for type A and B systems of equal height. As expected, the same also applies to $V_{\text {tot, } \mathrm{W}}$ at ULS $\left(=V_{\text {tot }} / W\right)$. However, of note is the reduced proportionality of base shear forces at ULS to building superstructure height as $H$ is increased. This is attributable to inverse proportionality of $V_{\text {tot }}$ and other maximum shear force flows at bases of shear walls to the fundamental period $T_{1}$ (i.e., $T_{1}$ proportional to $H$ ). Magnitudes of $V_{\text {tot }}, V_{\text {tot, } W}$ and $v_{\mathrm{sw}}$ are very similar for systems A-5 and B-5, but this has no particular significance other than indicating CLT shear-wall elements in those particular buildings are designed to essentially the same level of efficiency.

Values of average base shear per unit length of shear wall, $v_{\mathrm{sw}}$, are very sensitive to the adopted method of shear-wall anchoring. As Table 4 shows, $v_{\mathrm{sw}}$ values are only similar for systems 5-A and 5-B. Divergence is considerable in the case of eight storey systems, i.e., 31\% higher for 8-B than 8-A. The key point to be drawn from the presented $v_{\mathrm{sw}}$ results is design decisions, such as substitution of X-Rad connectors for conventional wall anchoring methods or introduction of supplementary tie-downs, substantially alters load paths in SFRS. This in turn gives engineers powerful means of using CLT and connections in efficient ways.

\subsection{Uplift Forces}

Neglecting system B-3, maximum uplift forces at the base of SFRS in Table 5 show shear walls in building cores transfer higher force flows than perimeter shear walls. Alterations in architectural and SFRS design decisions would change the specific results, but those results do not demonstrate general effectiveness of shear-wall placement decisions as a way of optimising SFRS designs. For example, in the case of type A systems, some of the reported uplift forces exceed capacities of current generation off-the-shelf hold-down anchors. In similar circumstances, designers could decide to either employ specially manufactured anchors or alter the shear-wall layout.

In the case of type B systems, using X-Rad connections in combination with supplementary tie-downs is an effective way of controlling and limiting uplift forces on individual anchoring devices. Both B-5 and B- 8 systems demonstrate manipulability of design choices which do not infringe on the ability to create unambiguous pathways for forces of easily handled magnitudes to flow harmlessly through SFRS into building foundations.

\subsection{Lateral Displacement and Inter-Storey Drift}

Selection of CLT elements and connections of all SFRS case studies was based on only satisfying ULS requirements. Discussion in this section addresses whether the studied superstructures and their SFRS would also satisfy damage limitation deformability performance requirements of Eurocode 8 [35]. Specifically, Eurocode 8 requires limitation of inter-story drift as a function of the characteristics of non-structural elements and related fixing systems. Here it is assumed the SFRS of buildings are clad with brittle non-structural elements, in which case the so-called reduction factor, $v$, is unitary and the limiting drift limit is $0.5 \%$.

In terms of absolute maximum lateral displacements $\left(\Delta_{i}\right.$, values in Table 6$)$ deformability of type A and type B buildings is roughly similar for three- and five-storey superstructures, but system A-8 sways toward its top significantly more than system B-5. In fact, for mid-rise CLT buildings, the tensile deformability of the anchoring system is responsible for most of the building's lateral displacement, and so adequate stiffening detail should be used when designing their connections. This key issue was demonstrated by various design studies of mid-to high-rise CLT buildings (e.g., [34]).

As Table 7 shows, only systems A-3, B-3 and B- 5 meet an inter-storey drift limit requirement of $0.5 \%$, i.e., $\theta_{\max } \leq 0.5 \%$. The design question in the cases of other systems would be how to most efficiently stiffen them to bring $\theta_{\max }$ values into line with the Eurocode 8 requirement. Answers to 
this lie in examination of $\theta_{\max }{ }^{\text {rok }}, \theta_{\max }$ she and $\theta_{\max }{ }^{\text {CLT }}$ of Table 6. Those values clarify that anchoring connection-related deformations $\theta_{\max }{ }^{\text {rok }}$ and $\theta_{\max }$ she have important roles in determining $\theta_{\max }$ values, and their collective and sometimes individual roles exceeded that of $\theta_{\max }{ }^{\mathrm{CLT}}$ (shear deformation of CLT elements) for all case study buildings. Specifically, the subdivision of drift contribution reported in Table 6 shows that for low-rise building the CLT panel deformation value is aligned with those due to the shear and rocking. Otherwise, for mid-rise CLT building, the CLT panel contribution is different for the two considered configurations: for case A5 and A8 the CLT deformation is 3-5 times lower with respect to the rocking deformation and is similar to the shear deformation; for the B5 and B8 the three contribute equally to global deformation because of the high stiffness of connection devices employed. The inescapable conclusion is that for SFRS of the type investigated to meet the limitations on inter-storey drift specified in Eurocode 8 or international codes with similar requirements, selecting stiffer shear wall anchoring connections would be most efficient approach.

\section{Conclusions}

Employing X-Rad or other types of high-capacity anchoring connections makes possible the creation of building superstructures having eight, and potentially more, storeys braced only by CLT shear walls, even in high seismicity regions. However, it is important to emphasise that proper selection of suitable arrangements of shear walls for particular buildings depends on accurate representation of the semi-rigid behaviours of various anchoring connections during linear dynamic analyses within seismic design. Numerical analyses presented here demonstrate the need during normal engineering design practices to avoid use of finite element or other design analyses which do not explicitly incorporate connection flexibilities while estimating parameters like fundamental natural periods, base shear and uplift forces, as well as inter-storey drift.

Specific conclusions applicable to multi-storey buildings laterally braced with combinations of core and perimeter CLT shear walls are:

- When designing SFRS of superstructures, a clear flow of seismic actions to the foundations needs to be found by defining a proper connection system for the CLT panels' assembly.

- If LFRS/SFRS have only conventional anchoring connections (e.g., hold-down ties and angle shear brackets), the definition of uncoupled resistant connection patterns between shear and tensile forces is desirable when designing because it ensures a beneficial redundancy of the building when overloaded provided by the actual biaxial bearing capacity of connections.

- Use of innovative X-Rad connections, thanks to their biaxial capacity and related installation pattern at panels' corners, allows reducing the number of devices needed. However, supplementary tie-downs are necessary for stiffening and strengthening the building with respect to the rocking deformation and uplift forces, respectively. Equivalent linear elastic static force seismic design methods have only limited accuracy even if applicable building superstructure regularity and height requirements, and construction element ductility of applicable design codes are met in full.

- Suitable stiffness and capacity information applicable to proprietary shear wall anchoring connections is available from manufacturers of products, preferably contained in third-party product assessment reports, only for certain devices.

Author Contributions: S.P. developed the numerical models and executed the numerical analyses. A.P. provided the background information on the X-Rad connectors and high-capacity hold-downs and brackets. C.L., D.C. and L.P. supported the project throughout. I.S. provided conceptual and editorial input. All authors participated in writing the article.

Funding: This research received no external funding.

Conflicts of Interest: The authors declare no conflict of interest. 


\section{References}

1. Department of Economic and Social Affairs of the United Nations. World Economic and Social Survey Sustainable Development Challenges; United Nations: New York, NY, USA, 2 July 2013; ISBN 978-92-1-109167-0.

2. Buchanan, A.H.; John, S.; Love, S. LCA and carbon footprint of multi-storey timber buildings compared with steel and concrete buildings. N. Z. J. For. 2013, 57, 9-18.

3. Foliente, G.C. History of Timber Construction. In Wood Structures: A Global Forum on the Treatment, Conservation, and Repair of Cultural Heritage STP13370S; Kelley, S., Loferski, J., Salenikovich, A., Stern, E., Eds.; ASTM International: West Conshohocken, PA, USA, 2000; pp. 3-22.

4. Ghobarah, A. Performance-based design in earthquake engineering: State of development. Eng. Struct. 2001, 23, 878-884. [CrossRef]

5. Follesa, M.; Vassallo, D.; Christovasilis, I.P. Seismic Design of a 10-Storey CLT Building; FPInnovation: Pointe-Claire, QC, Canada, August 2013.

6. Xiong, H.B.; Ouyang, L.; Wu, Y. Preliminary design of a novel hybrid tall building with concrete frame-tube and light wood boxes. In Proceedings of the World Conference on Timber Engineering (WCTE), Vienna, Austria, 22-25 August 2016; Eberhardsteiner, J., Winter, W., Fadai, A., Pöll, M., Eds.; Vienna University of Technology: Wien, Austria, 2016; ISBN 978-3-903039-00-1.

7. Loss, C.; Frangi, A. Experimental investigation on in-plane stiffness and strength of innovative steel-timber hybrid floor diaphragms. Eng. Struct. 2017, 138, 229-244. [CrossRef]

8. Smith, I.; Frangi, A. Use of Timber in Tall Multi-Storey Buildings; International Association for Bridge and Structural Engineering: Zurich, Switzerland, 8 May 2014; p. 186, ISBN 3857481323.

9. Connolly, T.; Loss, C.; Iqbal, A.; Tannert, T. Feasibility study of mass-timber cores for the UBC tall wood building. Buildings 2018, 8, 98. [CrossRef]

10. Brandner, R.; Flatscher, G.; Ringhofer, A.; Schickhofer, G.; Thiel, A. Cross laminated timber (CLT): Overview and development. Eur. J. Wood Wood Prod. 2016, 74, 331-351. [CrossRef]

11. Gavric, I.; Fragiacomo, M.; Ceccotti, A. Cyclic behaviour of typical metal connectors for cross-laminated (CLT) structures. Mater. Struct. 2015, 48, 1841-1857. [CrossRef]

12. Ceccotti, A.; Sandhaas, C.; Okabe, M.; Yasumura, M.; Minowa, C.; Kawai, N. SOFIE project-3D shaking table test on a seven-storey full-scale cross-laminated timber building. Earthq. Eng. Struct. 2013, 42, 2003-2021. [CrossRef]

13. Tomasi, R.; Smith, I. Experimental characterization of monotonic and cyclic loading responses of CLT panel-to-foundation and angle bracket connections. J. Mater. Civ. Eng. 2015, 27, 04014189. [CrossRef]

14. Dujic, B.; Aicher, S.; Zarnic, R. Investigation on in-plane loaded wooden elements-Influence of loading on boundary conditions. Otto Graf J. 2005, 16, 259-272.

15. Popovski, M.; Pei, S.; van de Lindt, J.W.; Karacabeyli, E. Force modification factors for CLT structures for NBCC. In Materials and Joints in Timber Structures; RILEM Bookseries 9; Aicher, S., Reinhardt, H.W., Garrecht, H., Eds.; Springer: Dordrecht, The Netherlands, 2014; pp. 543-553.

16. Ni, C.; Popovski, M. Mid-Rise Wood Frame Construction Handbook SP-57E; FPInnovation: Pointe-Claire, QC, Canada, 2015.

17. Polastri, A.; Izzi, M.; Pozza, L.; Loss, C.; Smith, I. Seismic analysis of multi-storey timber buildings braced with a CLT core and perimeter shear-walls. Bull. Earth. Eng. 2018, 1-20. [CrossRef]

18. Scotta, R.; Marchi, L.; Trutalli, D.; Pozza, L. A dissipative connector for CLT buildings: Concept, design and testing. Materials 2016, 9, 139. [CrossRef] [PubMed]

19. Karacabeyli, E.; Lum, C. Technical Guide for the Design and Construction of Tall Wood Buildings in Canada; FPInnovation: Pointe-Claire, Montreal, QC, Canada, 2014.

20. Schneider, J.; Shen, Y.; Stiemer, S.F.; Tesfamariam, S. Assessment and comparison of experimental and numerical model studies of cross-laminated timber mechanical connections under cyclic loading. Constr. Build. Mater. 2015, 77, 197-212. [CrossRef]

21. Gagnon, S.; Pirvu, C. CLT Handbook: Cross-Laminated Timber; FPInnovation: Pointe-Claire, Montreal, QC, Canada, 2011.

22. Izzi, M.; Casagrande, D.; Bezzi, S.; Pasca, D.; Follesa, M.; Tomasi, R. Seismic behaviour of Cross-Laminated Timber structures: A state-of-the-art review. Eng. Struct. 2018, 170, 42-52. [CrossRef] 
23. Zhang, X.; Popovski, M.; Tannert, T. High-capacity hold-down for mass-timber buildings. Constr. Build. Mater. 2018, 164, 688-703. [CrossRef]

24. Kramer, A.; Barbosa, A.R.; Sinha, A. Performance of steel energy dissipators connected to Cross-Laminated Timber wall panels subjected to tension and cyclic loading. J. Struct. Eng. 2015, 142, E4015013. [CrossRef]

25. Hashemi, A.; Zarnani, P.; Masoudnia, R.; Quenneville, P. Seismic resistant rocking coupled walls with innovative Resilient Slip Friction (RSF) joints. J. Constr. Steel Res. 2017, 129, 215-226. [CrossRef]

26. Pei, S.; van de Lindt, J.W.; Popovski, M.; Berman, J.W.; Dolan, J.D.; Ricles, J.M.; Sause, R.; Blomgren, H.; Rammer, D.R. Cross laminated timber for seismic regions: Progress and challenges for research and implementation. J. Struct. Eng. 2016, 142, E2514001. [CrossRef]

27. Pozza, L.; Scotta, R.; Trutalli, D.; Polastri, A.; Smith, I. Experimentally based q-factor estimation of cross laminated timber walls. Proc. ICE Struct. Build. 2016, 169, 492-507. [CrossRef]

28. Sustersic, I.; Fragiacomo, M.; Dujic, B. Seismic analysis of cross-laminated multistory timber buildings using code-prescribed methods: Influence of panel size, connection ductility, and schematization. J. Struct. Eng. 2016, 142, E4015012. [CrossRef]

29. Follesa, M.; Fragiacomo, M.; Casagrande, D.; Tomasi, R.; Piazza, M.; Vassallo, D.; Canetti, D.; Rossi, S. The new provisions for the seismic design of timber buildings in Europe. Eng. Struct. 2018, 168, 736-747. [CrossRef]

30. Pozza, L.; Ferracuti, B.; Massari, M.; Savoia, M. Axial-shear interaction on CLT hold-down connectionsExperimental investigation. Eng. Struct. 2018, 160, 95-110. [CrossRef]

31. RothoBlaas (RB). X-RAD Manual, 2018th ed.; RB: Cortaccia, Bolzano, Italy, 2018.

32. Polastri, A.; Giongo, I.; Piazza, M. An innovative connection system for CLT structures. Struct. Eng. Int. 2017, 27, 502-511. [CrossRef]

33. Polastri, A.; Angeli, A. An innovative connection system for CLT structures: Experimental-numerical analysis. In Proceedings of the World Conference on Timber Engineering (WCTE), Quebec City, QC, Canada, 10-14 August 2014.

34. Polastri, A.; Giongo, I.; Angeli, A.; Brandner, R. Mechanical characterization of a prefabricated connection system for Cross Laminated Timber structures in seismic regions. Eng. Struct. 2018, 167, 705-715. [CrossRef]

35. European Committee for Standardization (CEN). Design of Structures for Earthquake Resistance. Part 1: General Rules, Seismic Actions and Rules for Buildings. EN 1998-1, Eurocode 8; CEN: Brussels, Belgium, December 2004.

36. Smith, T.; Fragiacomo, M.; Pampanin, S.; Buchanan, A.H. Construction time and cost for post-tensioned timber buildings. Proc. Inst. Civ. Eng. Constr. Mater. 2009, 162, 141-149. [CrossRef]

37. Montaldo, V.; Meletti, C.; Martinelli, F.; Stucchi, M.; Locati, M. On-line seismic hazard data for the new Italian building code. J. Earthq. Eng. 2007, 11 (Suppl. 1), 119-132. [CrossRef]

38. Trutalli, D.; Pozza, L. Seismic design of floor-wall joints of multi-storey CLT buildings to comply with regularity in elevation. Bull. Earthq. Eng. 2018, 16, 183-201. [CrossRef]

39. Polastri, A.; Pozza, L. Proposal for a standardized design and modelling procedure of tall CLT buildings. Int. J. Qual. Res. 2016, 10, 607-624.

40. European Committee for Standardization (CEN). EN 338: Structural Timber—Strength Classes; CEN: Brussels, Belgium, October 2009.

41. European Organisation for Technical Approvals (EOTA). X-Lam Dolomiti-CLT: Cross Laminated Timber (CLT)_Solid Wood Slab Elements to Be Used as Structural Elements in Buildings; European Technical Approval ETA-12/0347; EOTA: Charlottenlund, Denmark, 2012.

42. RothoBlaas (RB). Wood Connectors and Timber Plates Manual, 2018th ed.; RB: Cortaccia, Bolzano, Italy, 2018.

43. Casagrande, D.; Polastri, A.; Sartori, T.; Loss, C.; Chiodega, M. Experimental campaign for the mechanical characterization of connection systems in the seismic design of timber buildings. In Proceedings of the World Conference on Timber Engineering (WCTE), Vienna, Austria, 22-25 August 2016; Eberhardsteiner, J., Winter, W., Fadai, A., Pöll, M., Eds.; Vienna University of Technology: Wien, Austria, 2016; ISBN 978-3903039-00-1.

44. European Committee for Standardization (CEN). EN 12512, Timber Structures. Test Methods. Cyclic Testing of Joints Made with Mechanical Fasteners; CEN: Brussels, Belgium, 28 September 2005.

45. European Organisation for Technical Approvals (EOTA). Three-Dimensional Nailing Plate (Angle Brackets and Hold-Downs for Timber-to-Timber or Timber-to-Concrete or Steel Connections); European Technical Assessment ETA-11/0086; EOTA: Charlottenlund, Denmark, 2015. 
46. European Organisation for Technical Approvals (EOTA). Three-Dimensional Nailing Plate (Angle Bracket for Timber-to-Timber or Timber-to-Concrete or Steel Connections); European Technical Assessment 11/0496; EOTA: Nordhavn, Denmark, 2014.

47. European Organisation for Technical Approvals (EOTA). Rotho Blaas X-RAD, European Technical Approval ETA-15/0632; EOTA: Vienna, Austria, 2015.

48. Dujic, B.; Strus, K.; Zarnic, R.; Ceccotti, A. Prediction of dynamic response of a 7-storey massive XLam wooden building tested on a shaking table. In Proceedings of the World Conference on Timber Engineering (WCTE), Riva del Garda, Italy, 21-24 August 2010.

49. Pozza, L.; Savoia, M.; Franco, L.; Saetta, A.; Talledo, D. Effect of different modelling approaches on the prediction of the seismic response of multi-storey CLT buildings. Int. J. Comput. Methods Exp. Meas. 2017, 5, 953-965. [CrossRef]

50. European Committee for Standardization (CEN). EN 1995-1-1:2004/A2 (2014) Eurocode 5: Design of Timber Structures. Part 1-1: General. Common Rules and Rules for Buildings; CEN: Brussels, Belgium, November 2014.

(C) 2018 by the authors. Licensee MDPI, Basel, Switzerland. This article is an open access article distributed under the terms and conditions of the Creative Commons Attribution (CC BY) license (http:/ / creativecommons.org/licenses/by/4.0/). 